
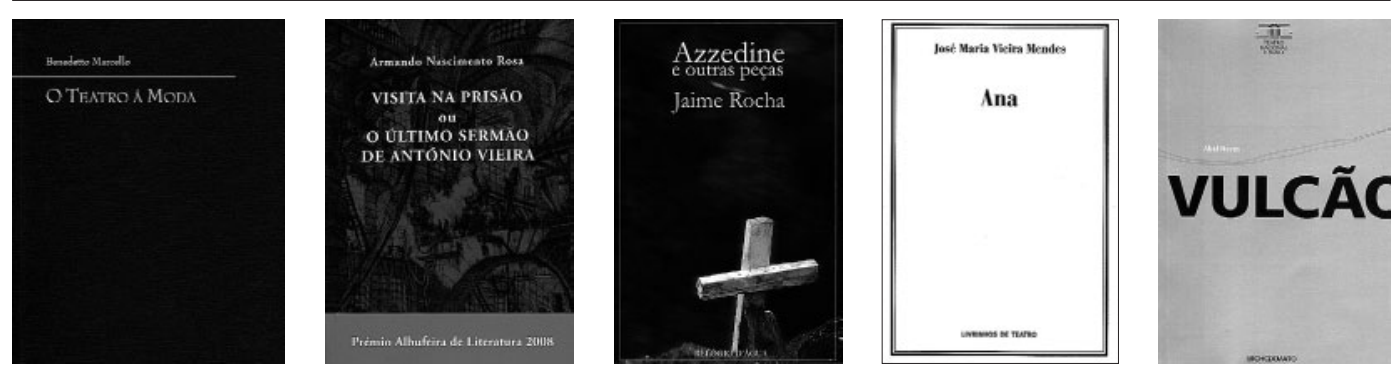

\title{
Publicações de teatro em 2009
}

\section{Lista compilada por Sebastiana Fadda}

\section{Peças originais (ou volumes de peças) em primeira edição}

AA.W., Palcos: Palcos novos, palavras novas (Coro dos maus alunos, de Tiago Rodrigues; Nós numa corda, de Miguel Castro Caldas; Refuga / Fugee, de Abi Morgan, trad. Francisco Frazão), Lisboa, Fundação Caixa Geral de Depósitos / Culturgest, 2009.

ÁVILA, Norberto, Algum teatro (vol. I: As histórias de Hakim, A paixão segundo João Mateus, As cadeiras celestes, O rosto levantado; vol. II: Viagem a Damasco, Do desencanto à revolta, Os deserdados da pátria, Florânia ou a perfeita felicidade, D. João no jardim das delícias; vol. III: Magalona Princesa de Nápoles, 0 marido ausente, As viagens de Henrique lusitano, A donzela das cinzas, Uma nuvem sobre a cama; vol. IV: Arlequim nas ruinas de Lisboa, Os doze mandamentos, Fortunato e TV Glória, 0 Café Centauro, Salomé ou a cabeça do profeta, Para além do caso Maddie), apresentação do autor, Lisboa, Imprensa Nacional-Casa da Moeda, 2009.

BRANDÃO, Raul / DELGADO, Alexandre, 0 doido e a morte, ed. de texto Miguel-Pedro Quadrio, s.l. [Viana do Castelo], Livros de Areia, 2009.

CONRADO, Júlio, 0 corno de oiro: Comédia em 3 actos, posfácio do autor, Lisboa, Roma Editora, 2009.

EIRAS, Pedro, Um punhado de terra: Monólogo, Porto, Deriva, 2009.

GARRET, Almeida, Frei Luís de Sousa / Falar verdade a mentir, Lisboa, Livraria Bertrand, 2009.

LOPES, João Carlos Santos, Ordem, Lisboa, INATEL / Teatro, 2009.

MACHADO, Carlos Alberto, 5 cervejas para o Virgílio, Lisboa, \&t etc, 2009.

MACHADO, Simão, Comédias (Comédia de Diu, Comédia da pastora Alfea), introd. José Xavier Rodríguez Rodríguez, edição de José Camões, José Xavier Rodríguez Rodríguez e Helena Reis Silva, Lisboa, Imprensa Nacional-Casa da Moeda, 2009.

MATOS, Maria Vitalina Leal de, A paixõo segundo Fernando Pessoa: Guião para um espectáculo, Lisboa, Edições Colibri, 2009.

MENDES, José Maria Vieira, Ana, Lisboa, Artistas Unidos / Livros Cotovia, Livrinhos de Teatro n. 39, 2009.
MESQUITA, Marcelino, Teatro completo (vol. IV: Pedro, o cruel, Margarida do monte, Envelhecer, Perina, A mentira, Frineia, Na voragem, 0 cão do regimento), org. Duarte Ivo Cruz, Lisboa, Imprensa Nacional-Casa da Moeda, 2009.

MEXIA, Pedro, Nada de dois: Tragicomédia, Lisboa, Tintada-China, 2009.

NEVES, Abel, Vulcão, Lisboa, Teatro Nacional D. Maria II / Bicho do Mato, 2009.

ROCHA, Jaime, Azzedine e outras peças (Morcegos, Homens como tu, 0 mal de Ortov, No ervilhal), Lisboa, Relógio d'Água, 2009.

ROSA, Armando Nascimento, Visita na prisão ou 0 último sermão de António Vieira, Lisboa, Assírio \&t Alvim, A Phala / 37, 2009.

SAMPAI0, Jaime Salazar, Lanterna mágica (peças curtas, curtinhas e encurtadas), pref. António Braz Teixeira, Lisboa, Dimensão 6, 2009.

SOBRAL, Augusto, Teatro (vol. II: O bigode, Estou na muralha à tua espera, Inexistência - é uma comédia), pref. António Braz Teixeira, Lisboa, Imprensa Nacional-Casa da Moeda, 2009.

VICENTE, Gil, Breve sumário da história de Deus, com pinturas de Ilda David' no Teatro Nacional São João e um ensaio de José Augusto Cardoso Bernardes, Lisboa, Assírio \&t Alvim, 2009. 

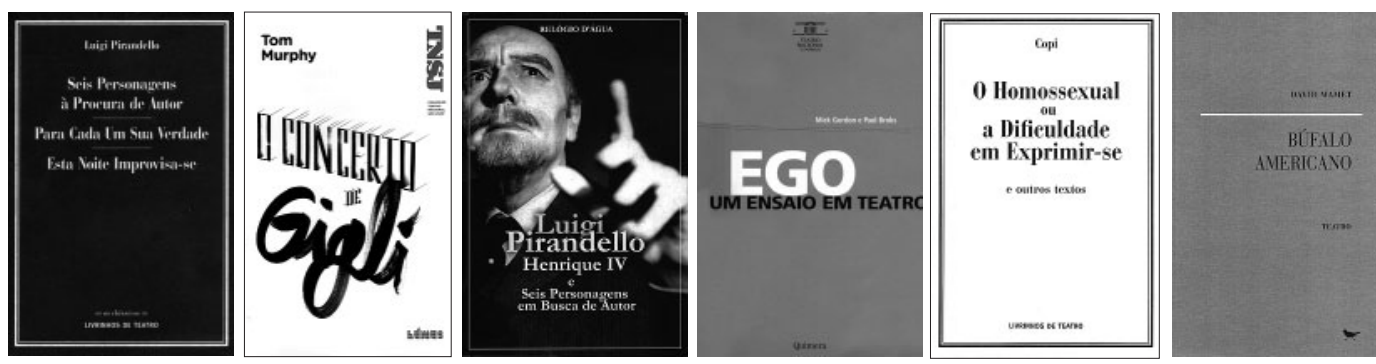

\section{Traduções}

BAILLY, Jean-Christophe, Uma noite na biblioteca, trad. Christine Zurbach e Luís Varela, Lisboa, Livros Cotovia 2009.

BRECHT, Bertolt, A mãe, trad. Yvette K. Centeno e Teresa Balté, s.l. [Viana do Castelo], Livros de Areia, 2009.

COPI, O homossexual ou a dificuldade em exprimir-se e outros textos (Loretta Strong, A Torre de La Défense, O Frigorifico), trad. Luis Castro, Luis Caminha, Olinda Gil, Isabel Alves, Lisboa, Artistas Unidos / Livros Cotovia, Livrinhos de Teatro n. ${ }^{\circ}$ 40, 2009.

EURÍPIDES, Tragédias (vol. I: Ciclope, Alceste, Medeia, Heraclidas), introd. geral Maria de Fátima Sousa e Silva, introd., trad. e notas de Carmen Leal Soares, Nuno Simões Rodrigues, Maria Helena da Rocha Pereira e Claúdia Raquel Cravo da Silva, Lisboa, Imprensa Nacional-Casa da Moeda, 2009.

GÓGOL, Nikolai, O inspector geral: Comédia em cinco actos, trad. e introd. Nina Guerra e Filipe Guerra, Lisboa, Assírio \&t Alvim, 2009.

GOLDONI, Carlo, Peças escolhidas 2 (Os rústicos, A casa nova, As zaragatas em Chiozza), pref. Maria João Almeida, trad. José Peixoto e Luis Nogueira, posfácio Jorge Silva Melo, Lisboa, Livros Cotovia, Teatro, 2009

GORDON, Mick / BROKS, Paul, Ego: Um ensaio em teatro, trad. Francisco Nicéforo, Lisboa, Teatro Nacional D. Maria II / Quimera, 2009.

HARWOOD, Ronald, 0 camareiro, trad. Maria João da Rocha Afonso, Lisboa, Teatro Nacional D. Maria II / Quimera, 2009.

LETTS, Tracy, Agosto em Osage, trad. Pedro Gorman, Lisboa, Teatro Nacional D. Maria II / Quimera, 2009

MAMET, David, Búfalo americano, trad. Telmo Rodrigues, Lisboa, Livros Cotovia, 2009.

MURPHY, Tom, 0 concerto de Gigli, trad. e posfácio Paulo Eduardo Carvalho, Porto / Vila Nova de Famalicão, Teatro Nacional S. João / Húmus, 2009.

PIRANDELLO, Luigi, Seis personagens à procura de autor / Para cada um a sua verdade / Esta noite improvisase, trad. Mário Feliciano, Fernando José Oliveira, Natércia Freire, Maria da Graça Freire José Alberto Osório Mateus e Luís Miguel Cintra revistas por José Maria Vieira Mendes e Jorge Silva Melo; Lisboa, Artistas Unidos / Livros Cotovia, Livrinhos de Teatro n. ${ }^{\circ}$ 36, 2009.

- -, Henrique IV/Seis personagens em busca de autor, trad. Margarida Periquito e Sandra Escobar, Lisboa, Relógio d'Água, 2009.

- -, Seis personagens à procura de um autor, trad. Daniel Jonas, Lisboa, Livros Cotovia, Teatro, 2009.
PLAUTO, Comédias (vol. II: A comédia da cestinha, Cásina Epídico, Gorgulho e Os dois Menecmos), introd. geral de Aires Pereira do Couto, introd. trad. e notas de Carlos Alberto Louro Fonseca, Aires Pereira do Couto, Walter de Medeiros, Cláudia Teixeira e Helena Costa Toipa, Lisboa, Imprensa Nacional-Casa da Moeda, 2009.

SCHWARTZ, Jenny, A orelha de Deus, trad. Rogério Casanova, Lisboa, Artistas Unidos / Culturgest / Livros Cotovia, Livrinhos de Teatro, n. ${ }^{\circ}$ 38, 2009.

SHAKESPEARE, William / AUDEN, W.H., A tempestade, seguido de 0 mar e o espelho, trad. José Manuel Mendes, Luis Lima Barreto, Luís Miguel Cintra e Daniel Jonas Lisboa, Livros Cotovia, 2009.

SÓFOCLES, Rei Édipo, introd., trad. e notas Maria do Céu Zambujo Fialho, Lisboa, Edições 70, 2009.

STEPHENS, Simon, Harper Regan, trad. Jorge Carvalho, Lisboa, Teatro Nacional D. Maria II / Quimera, 2009.

STRINDBERG, August, Menina Júlia, trad. Augusto Sobral, revista a partir do sueco por Tânia Filipe, Lisboa, Teatro Nacional D. Maria II / Quimera, 2009.

WALSH, Enda, Acamarrados / A farsa da Rua W/As pequenas coisas, trad. Joana Frazão, Lisboa, Artistas Unidos / Livros Cotovia, Livrinhos de Teatro n 37 , 2009.

WILLIAMS, Tennessee, Um eléctrico chamado desejo e outras peças (Gata em telhado de zinco quente, Subitamente, no Verão passado, Verão e fumo), trad. Helena Briga Nogueira, Lisboa, Relógio d'Água, 2009.

\section{Traduções em reedição}

ARISTÓFANES, As rãs, trad. Américo da Costa Ramalho, Coimbra, FESTEA, 2.a ed., 2009.

ÉSOUILO, Persas, trad. e notas Manuel Oliveira Pulquério, Lisboa, Edições 70, 2. ${ }^{\text {ed., }} 2009$. 


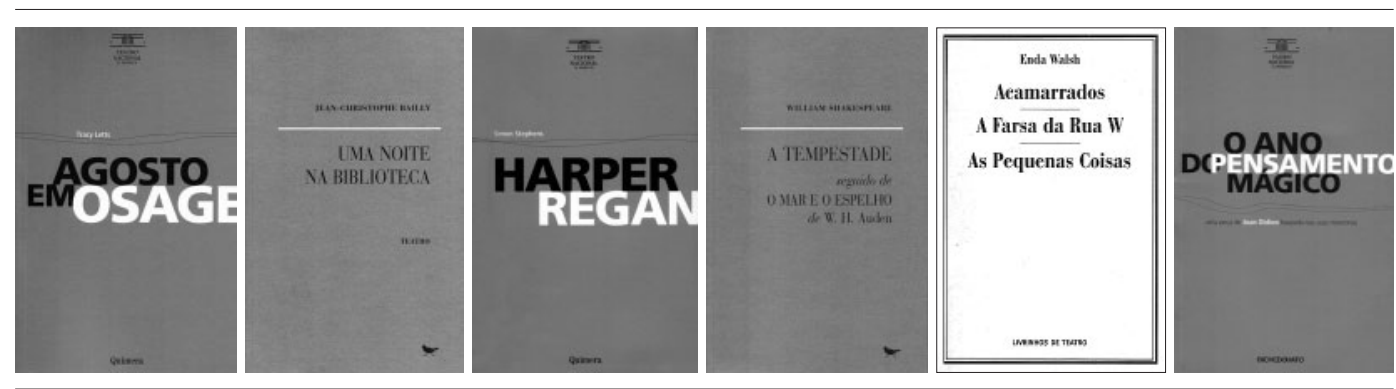

\section{Estudos / Documentos}

AA. W, Teatro do mundo: Teatro e justiça, afinidades electivas, Porto, Centro de Estudos Teatrais da Universidade do Porto, 2009.

ALMEIDA, Clara de, Irene, nome de paz, Quinta do Conde, ContraMargem, 2009.

BARATA, José Oliveira, Máscaras da utopia: História do teatro universitário em Portugal 1938-74, Lisboa, Fundação Calouste Gulbenkian, 2009.

BARROS, Júlia Leitão, Amélia Rey Colaço: Fotobiografias século XX, Rio do Mouro, Círculo de Leitores, 2009.

BRILHANTE, Maria João / PINHEIRO, Paula Moura, Tété: Estória da pré-história do Chapitô 1946/1987, coord. e pesquisa histórica Maria João Brilhante, registo biográfico Paula Moura Pinheiro, design gráfico Henrique Cayatte, Lisboa, Chapitô, 2009.

BRITES, João (dir.), Teatro Bando: afectos e reflexos de um trajecto, Palmela, Cooperativa de Produção Artística Teatro de Animação 0 Bando, 2009.

CASTELO-BRANCO, Salva (dir.), Enciclopédia da música em Portugal no século XX, Lisboa, Círculo de Leitores, 1. ${ }^{\circ}$ vol., 2009.

CARVALHO, Paulo Eduardo, Identidades reescritas: Figurações da Irlanda no teatro português, Porto, Edições Afrontamento e Instituto de Literatura Comparada Margarida Losa, 2009.

COELHO, Rui Pina, Casa da Comédia (1946-1975): Um palco para uma ideia de teatro, Lisboa, Imprensa Nacional-Casa da Moeda, 2009.

DOLORES, Carmen / LIVIO, Tito, Teatro Moderno de Lisboa (1961-1965), Lisboa, Editorial Caminho, 2009.

FALCÃO, Miguel, Espelho de ver por dentro: 0 percurso teatral de Alves Redol, pref. Maria Helena Serôdio, Lisboa, Imprensa Nacional-Casa da Moeda, 2009.

KLEIST, Heinrich Von, Sobre o teatro de marionetas e outros escritos, trad. e apresentação José Miranda Justo, Lisboa, Antígona, 2009.

LIBERAL, Ana Maria / PEREIRA, Rui / ANDRADE, Sérgio C., Casas da música no Porto: Para a história da cidade, 1. ${ }^{\circ}$ vol.: Séculos XVIII e XIX, Porto, Casa da Música, 2009.

MARCELLO, Benedetto, 0 teatro à moda, ed. José Camões e Filipa Freitas, Lisboa, Centro de Estudos de Teatro da Universidade de Lisboa, 2009.

OLIVEIRA, Camilo de, O actor do povo. / As regras da minha vida, Lisboa, Guimarães Editora, 2009.

RAMOS, Fernando Mora / RODRIGUES, Américo / FERREIRA, José Luis / PORTELA, Manuel, Quatro ensaios à boca de cena: Para uma politica teatral e da programação, Lisboa, Livros Cotovia, 2009.
SARRAZAC, Jean-Pierre, A invenção da teatralidade, seguido de Brecht em processo e 0 jogo dos possiveis, trad. e apresentação Alexandra Moreira da Silva, Porto, Deriva Editores, 2009.

SERÔDIO, Maria Helena / FLOR, João Almeida / ROSA, Alexandra Assis / BARROS, Rita Queiroz de / CARVALHO, Paulo Eduardo (orgs.), Shakespeare entre nós, ed. CEAUL / CET(Centro de Estudos Anglísticos da Universidade de Lisboa / Centro de Estudos de Teatro da Universidade de Lisboa), Ribeirão, Húmus, 2009.

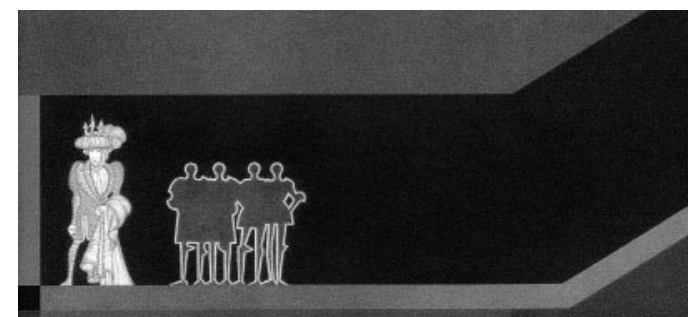

\section{Shakespeare entre nós}

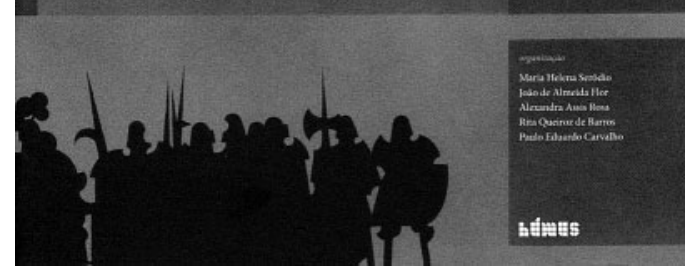

\section{Publicações periódicas}

Artistas Unidos: Revista, n. 23 (Junho 2009), dir. Jorge Silva Melo, Lisboa, Livros Cotovia.

Cine Qua Non: música/dança/teatro/artes visuais/literatura/cinema, n. 1 (Verão / Outono de 2009) revista bilingue (português / inglês), dir. Ana Luísa Valdeira da Silva, Centro de Estudos Anglísticos da Universidade de Lisboa.

Obscena: Revista de artes performativas, n. ${ }^{1} 18$ (FevereiroMarço 2009), n.o 19 (Abril-Maio 2009), n. 20 (JulhoAgosto 2009) e n. 21 (Novembro-Dezembro 2009), dir. Tiago Bartolomeu Costa, Lisboa.

Sinais de cena, n.`s 11 (Junho 2009) e 12 (Dezembro 2009), dir. Maria Helena Serôdio, Associação Portuguesa de Críticos de Teatro \& Centro de Estudos de Teatro, Húmus. 


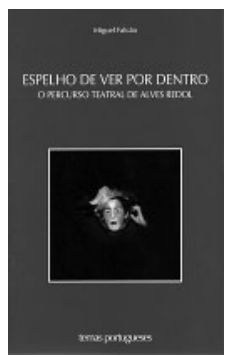

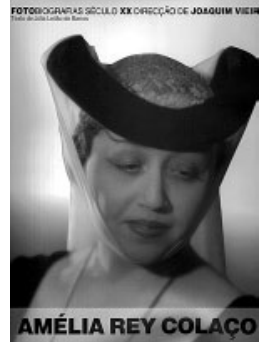

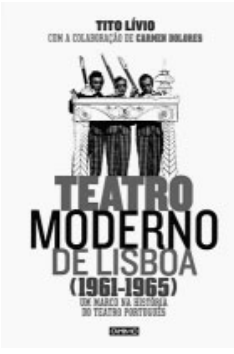

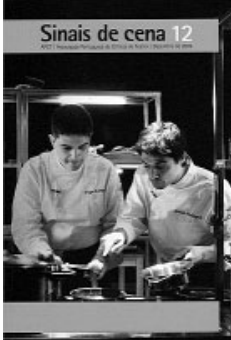

Adenda à lista publicada na Sinais de cena $n .^{\circ} 11$ (2008)

AA. W, Teatro do mundo: What's our Life? A play of passion Lugares do palco, espaços da cidade, Porto, Centro de Estudos Teatrais da Universidade do Porto, 2008. [estudos / documentos]

EURÍPIDES, Medeia, introd., versão do grego e notas de Maria Helena da Rocha Pereira, Lisboa, Fundação Calouste Gulbenkian, Serviço de Educação e Bolsas, 4. ${ }^{a}$ ed., 2008. [tradução em reedição]

GOLDONI, Carlo, O café, trad. Isabel Lopes e Fernando Mora Ramos, posfácio Fernando Mora Ramos, Porto, Campo das Letras / Teatro Nacional São João, 2008. [peça]

GUERREIRO, Mónica, Olga Roriz, Lisboa, Assírio \&t Alvim, 2008. [estudos / documentos]

RIBEIR0, Jorge, José Cayolla: Um aristocrata do teatro, Porto, Campo das Letras, 2008.

SÓFOCLES, Antígona, introd., versão do grego e notas de Maria Helena da Rocha Pereira, Lisboa, Fundação Calouste Gulbenkian, 8. ${ }^{a}$ ed., 2008. [tradução em reedição]

TORRAD0, António, Zaca Zaca, ilustrações António Pilar Lisboa, Editorial Caminho, 2008. [peça, nova edição]

Adenda à lista publicada na

Sinais de cena $n .^{\circ} 9$ (2007)

AA. W, Teatro do mundo: 0 teatro na universidade, ensaio e projecto, Porto, Centro de Estudos Teatrais da Universidade do Porto, 2007. [estudos / documentos]

AA. W, Teatro do mundo: Linguagens barrocas do teatro europeu, Porto, Centro de Estudos Teatrais da Universidade do Porto, 2007. [estudos / documentos]

Adenda à lista publicada na
Sinais de cena $n .^{\circ} 7$ (2006)

FERREIRA, António, Castro e Poemas lusitanos, introdução e notas Silvério Augusto Benedito, Lisboa, Editorial Verbo, 2006. [peça]
Adenda à lista publicada na Sinais de cena $n .^{\circ} 5$ (2005)

ARISTÓFANES, Pluto (A riqueza), trad. Américo da Costa Ramalho, Coimbra, FESTEA, 2005. [tradução]

- -, As mulheres no parlamento, trad. Maria de Fátima Sousa e Silva, Coimbra, FESTEA, 2005. [tradução]

DE WEND FENTON, Rose / NEAL, Lucy, The Turning World: Stories from the London International Festival of Theatre, Lisboa, Fundação Calouste Gulbenkian, 2005. [estudos / documentos]

GARRETT, Almeida, Um auto de Gil Vicente, Porto, Porto Editora, Mundo das Letras, 2005. [peça]

SÁ DE MIRANDA, Francisco de, Poesia e teatro, selecção e introdução Silvério Augusto Benedito, Lisboa, Editorial Verbo, Verbo Clássicos, 2005. [peça]

\section{Adenda à lista publicada na} Sinais de cena $n .^{\circ} 3(2004)$

ARISTÓFANES, As rãs, trad. Américo da Costa Ramalho, Coimbra, FESTEA, 2004. [tradução] 